\title{
Changing the characteristics and properties of zeolite $Y$ and nano-anatase in the formation of a nano-anatase/Y composite with improved photocatalytic and adsorption properties
}

\author{
E. N. Domoroshchina ${ }^{1}$ (D) - V. V. Chernyshev ${ }^{2}$ - G. M. Kuz'micheva ${ }^{1} \cdot$ A. V. Dorokhov ${ }^{1} \cdot$ L. V. Pirutko $^{3} \cdot$ G. V. Kravchenko $^{1}$. \\ R. B. Chumakov ${ }^{4}$
}

Received: 21 July 2017 / Accepted: 4 December 2017 / Published online: 3 February 2018

(c) Springer-Verlag GmbH Germany, part of Springer Nature 2018

\begin{abstract}
Zeolite $\mathrm{Y}$ and the NTD/Y nanocomposite, which were synthesized in situ (the addition of zeolite $\mathrm{Y}$ to the reaction mixture in the course of the synthesis of NTD by the sulfate method), were studied by a variety of methods. The decrease in the particle size (scanning electron microscopy) and the water content in pores (X-ray powder diffraction study, the full-profile Rietveld method, IR spectroscopy, differential scanning calorimetry), the increase in OH groups content and the decrease in the water content on the surface of zeolite (X-ray photoelectron spectroscopy) in the composition of NTD/Y compared to the initial zeolite $\mathrm{Y}$ were all established. A larger specific surface area of NTD/Y (Brunauer-Emmet-Teller method) compared to the initial zeolite $\mathrm{Y}$ is due to the fact that zeolite $\mathrm{Y}$ in the nanocomposite contains a smaller amount of water because of the synthesis conditions and the presence of nanocrystalline NTD on the surface of zeolite particles. It was found that NTD/Y nanocomposite exhibits a higher photocatalytic activity in the model decomposition reaction of methyl orange under UV and adsorption capacity for the extraction of $\mathrm{P}(\mathrm{V})$ and $\mathrm{As}(\mathrm{V})$ ions from aqueous media compared to the initial zeolite and pure NTD obtained under the same conditions, which differs from NTD/Y by the larger particle size, the smaller specific surface and the smaller content of $\mathrm{OH}$ groups and water on the surface. The role of Bronsted and Lewis centers in the realization of properties is discussed.
\end{abstract}

Keywords Zeolite Y · Nanosized titanium dioxide · Nanocomposite · Crystalline structure and microstructure · Adsorption and photocatalytic properties

E. N. Domoroshchina

elena7820@gmail.com

1 Department of Materials Science and Technology of Functional Materials and Structures, Moscow Technological University, MITHT, 86 Vernadsky Avenue, Moscow, Russia 119571

2 Lomonosov Moscow State University, GSP-1, 1-3 Leninskiye Gory, Moscow, Russia 119991

3 Boreskov Institute of Catalysis, Siberian Branch of the Russian Academy of Sciences, pr. Lavrentieva 5, Novosibirsk, Russia 630090

4 National Research Center 'Kurchatov Institute', 1, Akademika Kurchatova pl, Moscow, Russia 123182

\section{Introduction}

Zeolites are aluminosilicates having a high porous specific surface area and the controlled pore, channel, and cavity sizes. Zeolites $\mathrm{Y}$ have different forms: NaY zeolite synthesized from sodium aluminosilicate gels (Breck 1974), $\mathrm{NH}^{4+}$ and $\mathrm{HY}$ zeolites prepared from zeolite $\mathrm{Y}$ by ion exchange with $\mathrm{NH}_{4} \mathrm{Cl}$ (Liu et al. 1992) or by ion exchange of the initial compensating cations with ammonium ions or polyvalent metal cations followed by the thermal treatment (Serykh 2014), and USY zeolite characterized by a large bulk $\mathrm{Si} / \mathrm{Al}$ ratio $(\mathrm{Si} / \mathrm{Al}>5)$, which was subjected to several hydrothermal treatments by Park et al. (2003). Different forms of zeolites $\mathrm{Y}$ are characterized by high acid resistance, thermal stability, and catalytic activity in cracking, isomerization, alkylation, and so on. Due to high reactivity, these zeolites are of high demand in oil refining and petrochemistry, in particular, as an active component 
of cracking catalysts. Besides, zeolites $\mathrm{Y}$ of different compositions and modules have adsorption (Galhotra et al. 2009; Klein et al. 1994) and antibacterial properties (Kubota et al. 2008).

Nanosized titanium dioxides (NTD) are photostable and environmentally safe, have high quantum yield for the UV photocatalytic oxidation, and exhibit adsorption properties due to the formation of highly reactive surface hydroxyl groups (Demina et al. 2014; Dadachov 2006). In addition, NTD show a bactericidal effect against pathogenic microorganisms (Ismagilov et al. 2009).

According to the literature data, NTD/Y nanocomposites combine the properties of the initial components: photocatalytic (Domoroshchina et al. 2017; Kuwahara et al. 2012; Wang et al. 2008, 2015; Kamegawa et al. 2013; Jansson et al. 2015; Maraschi et al. 2014), adsorption (Domoroshchina et al. 2017; Kravchenko et al. 2016; Zendehdel et al. 2014), and bactericidal (Domoroshchina et al. 2017).

Photocatalytic properties of nanocomposites NTD/Y on the decomposition of organic pollutants from the gas phase and the aqueous medium are most studied: photocatalytic degradation of 2-propanol in water (Kuwahara et al. 2012; Kamegawa et al. 2013), C.I. Basic Violet 10 in suspension (Wang et al. 2008), marbofloxacin and enrofloxacin in water (Maraschi et al. 2014), Methyl Orange dye in water (Domoroshchina et al. 2017; Wang et al. 2015), formaldehyde and trichloroethylene in gas phase under UV (Jansson et al. 2015) and the degradation of 2-propanol in water under visible light (Kamegawa et al. 2013).

Adsorption properties of NTD/Y for the extraction of the following dyes were studied: methylene blue (Zendehdel et al. 2014) and phenosafranine dye (Easwaramoorthi and Natarajan 2009), which are adsorbed on the surface of NTD/Y particles, and amaranth dye (Alwash et al. 2013), in relation to which NTD/Y does not exhibit adsorption activity. The adsorption of $\mathrm{P}(\mathrm{V})$ ions from aqueous media in the presence of NTD/Y nanocomposite was studied by Domoroshchina et al. (2017) and Kravchenko et al. (2016).

Nanocomposites NTD/zeolite can be conditionally divided into two groups, depending on the level and nature of the interaction of zeolite and NTD. Group I includes nanocomposites that are a mixture of NTD and zeolite with altered microstructural characteristics (NTD-polycrystalline, nanocrystalline or amorphous and its localization; the morphology and size of all levels of zeolite and NTD particles) in the nanocomposite composition. Group II includes nanocomposites, the formation of which changed the characteristics of the crystal structure of NTD or/and zeolite. The characteristics of each group separately, or of group I and group II together can be realized in one composite and the physical-chemical properties of the nanocomposite (the composition of the surface; specific surface area, pore size, etc.) are changed.
The level and nature of the interaction of components depend on the methods and conditions for obtaining nanocomposites and determine their properties.

The following methods are currently used for the synthesis of nanocomposites NTD/Y:

- Ion exchange between the $\mathrm{Na}^{+}$and $\mathrm{NH}^{4+}$ forms of zeolite $\mathrm{Y}$ in an aqueous solution of $\left(\mathrm{NH}_{4}\right)_{2}(\mathrm{TiNO})\left(\mathrm{C}_{2} \mathrm{O}_{4}\right)_{2}$ followed by calcination at $400-550{ }^{\circ} \mathrm{C}$ (nanocrystalline NTD in NTD/Y) (Liu et al. 1992; Zhang et al. 1995; Alwash et al. 2013; Easwaramoorthi and Natarajan 2009);

- Wet impregnation of zeolite NaY (Alwash et al. 2013; Kuwahara et al. 2012; Wang et al. 2008) or HY (Kamegawa et al. 2013) with a $\mathrm{TiO}_{2}$ sol followed by evaporation of the liquid, drying, and calcination at $350-600{ }^{\circ} \mathrm{C}$ (amorphous (Alwash et al. 2013) or nanocrystalline (Wang et al. 2008) NTD in NTD/Y);

- Mechanical mixing of NTD, which was synthesized by the sol-gel method (Maraschi et al. 2014), via the hydrolysis of titanium isopropoxide (Xu and Langford 1997) or a solution of titanium tetraisopropoxide in ethanol (Ito et al. 2014), with HY zeolite (Maraschi et al. 2014) or NaY zeolite (Xu and Langford 1997; Ito et al. 2014); the separation of the precipitate, washing, drying, and annealing at $350-450{ }^{\circ} \mathrm{C}$ [nanocrystalline NTD in NTD/Y (Xu and Langford 1997; Ito et al. 2014)];

- A sol-gel method using titanate $n$-butyl acetate followed by annealing at $400{ }^{\circ} \mathrm{C}$ (Easwaramoorthi and Natarajan 2009; Wang et al. 2015), the degree of crystallinity of the composite decreases with an increase in $\mathrm{TiO}_{2}$ loading (Easwaramoorthi and Natarajan 2009); amorphous NTD in NTD/Y (Wang et al. 2015);

- Method in situ using $\mathrm{TiOSO}_{4} \cdot \mathrm{H}_{2} \mathrm{SO}_{4} \cdot y \mathrm{H}_{2} \mathrm{O}$ as precursor (nanocrystalline NTD in NTD/Y) (Kravchenko et al. 2016);

- Modified method of cold impregnation: co-dispersion of NTD (Hombifine $N$ with anatase or sample with $\eta$-phase) and zeolite $\mathrm{Y}$ in a dilute $\mathrm{KOH}$ solution with a subsequent microwave treatment (amorphous NTD in $\eta$-phase/Y, nanocrystalline NTD in Hombifine N/Y) (Kravchenko et al. 2016).

In NTD/Y nanocomposites synthesized by the ion exchange reaction (Liu et al. 1992; Zhang et al. 1995; Alwash et al. 2013), nanocrystalline NTD occupies zeolite cavities (group II), as it was demonstrated by X-ray photoelectron spectroscopy (XPS), IR spectroscopy, X-ray powder diffraction, scanning (SEM) and transmission electron microscopy (TEM). In NTD/Y synthesized by wet impregnation (Alwash et al. 2013; Jansson et al. 2015) or mechanical mixing techniques (Maraschi et al. 2014), amorphous (Alwash et al. 2013), and presumably, nano-anatase (Jansson 
et al. 2015) are present only on the surface of the zeolite (group I) [Energy-dispersive X-ray spectroscopy (EDS), $\mathrm{X}$-ray powder diffraction]. The application of the sol-gel method results in the formation of samples containing amorphous NTD both on the surface and within the zeolite framework (groups I + II) [IR spectroscopy, X-ray powder diffraction, SEM, Brunauer-Emmett-Teller method (BET)] (Wang et al. 2015).

The location of NTD particles in the NTD/Y nanocomposite depends not only on the method of synthesis and additional treatment (microwave and/or high-temperature annealing), which facilitates the incorporation of nanocrystalline NTD into the zeolite framework (group II) (Liu et al. 1992; Zhang et al. 1995; Alwash et al. 2013), but also on the amount of the introduced NTD and its characteristics, in particular, the particle size and the state of the starting NTD (amorphous or nanocrystalline). An increase in the NTD loading leads to the filling of the zeolite pores and the partial location of amorphous NTD on the zeolite surface (groups I + II) (Wang et al. 2015), whereas smaller NTD particles promote a more uniform distribution of NTD over the zeolite surface (group I) (Maraschi et al. 2014) or the insertion of nanocrystalline NTD into the zeolite framework (group II) (Liu et al. 1992; Zhang et al. 1995). The amorphous state of the starting NTD facilitates a more uniform distribution of nanoparticles on the zeolite surface (group I) compared to nanocrystalline Degussa P25 (Maraschi et al. 2014).

Analysis of the literature data indicates the relationship between the photocatalytic activity of NTD/Y and the modification of NTD (Domoroshchina et al. 2017), particles size (Maraschi et al. 2014) and the position of NTD in the nanocomposite (on the surface of the zeolite or in its pores) (Easwaramoorthi and Natarajan 2009), the zeolite modulus (Alwash et al. 2013), the specific surface (Zhang et al. 2013) and hydrophilicity/hydrophobicity (Alwash et al. 2013) of the nanocomposite NTD/Y as well as the relationship between adsorption properties of nanocomposite and its hydrophilicity/hydrophobicity (Alwash et al. 2013) and the position of NTD in NTD/Y (Easwaramoorthi and Natarajan 2009).

The goal of the present study is to study the structural behavior of zeolite $\mathrm{Y}$ and NTD in the in situ synthesized NTD/Y nanocomposite and substantiate the observed change in NTD/Y properties compared to the initial Y and NTD.

\section{Experimental}

\section{Synthetic procedures}

Zeolite Y, which was used as a template for the NTD/Y nanocomposite, has the protonated form $\mathrm{HNaY}$ (partial replacement of $\mathrm{Na}^{+}$with $\mathrm{H}^{+}$) with the formula
$\mathrm{Na}(\mathrm{H})_{58}\left[\mathrm{Al}_{58} \mathrm{Si}_{134} \mathrm{O}_{384}\right]\left(\mathrm{H}_{2} \mathrm{O}\right)_{240}(\mathrm{Si} / \mathrm{Al}=2.3)$. The zeolite $\mathrm{Y}$ was synthesized in the Boreskov Institute of Catalysis, Siberian Branch of the Russian Academy of Sciences, by a procedure described by Ginter et al. (1992).

The NTD/Y nanocomposites were synthesized in situ (Kravchenko et al. 2016) by the addition of zeolite $Y$ $(0.25 \mathrm{~g})$ to the reaction mixture in the course of the synthesis of NTD via short-term hydrolysis of titanyl sulfate, $\mathrm{TiOSO}_{4} \cdot x \mathrm{H}_{2} \mathrm{SO}_{4} \cdot y \mathrm{H}_{2} \mathrm{O}$, (7.35 g) with the subsequent heating to $95( \pm 2){ }^{\circ} \mathrm{C}$, separation of the resulting solid phase by vacuum filtration, washing with water and acetone, and drying in a drying oven for $30 \mathrm{~min}$ at $t=90^{\circ} \mathrm{C}$.

\section{Methods}

X-ray powder diffraction analysis. The X-ray powder diffraction patterns were collected in a rotation mode on a HZG-4 diffractometer (a plane graphite monochromator, $\mathrm{CuK} \alpha$ radiation, diffracted beam) in a step scan mode (the count time was $10 \mathrm{~s}$ per step, the step size was $0.02^{\circ}$, the $2 \theta$ angle range was $2^{\circ}-50^{\circ}$ or $80^{\circ}$ ). The qualitative phase analysis of samples with nanocomposites was carried out using the database PCPDFWIN PDF-2 and (Treacy and Higgins 2007). The sizes of NTD crystallites in NTD/Y $(D, \mathrm{~nm})$ are determined from the following formula: $D=0.9 \lambda / \beta \cos \theta$, where $\lambda$ is the wavelength, $\mathrm{Cu} K \alpha=1.54051 \AA$, $2 \theta \sim 25^{\circ}$, and $\beta$ is the integrated peak width. The standard deviation is $5 \%$.

High-accuracy synchrotron measurements of $\mathrm{Y}$ and NTD/Y samples were performed on the high-resolution powder diffraction beamline ID22 at the European Synchrotron Radiation Facility (ESRF, Grenoble, France). The beamline is equipped with a water-cooled Si 111 silicon double-crystal monochromator and a Si 111 analyzer (Fitch 2004). A powdered sample was loaded into a 1-mm diameter thin-walled borosilicate glass capillary, which was rotated at a rate of 1200 revolutions per minute for better counting statistics. The NIST Si 640c reference material was used as a standard for calibration of the goniometer and the refinement of the X-ray wavelength $[\lambda=0.399927(13) \AA]$. The X-ray diffraction data were collected in the $2 \theta$ angle range of $1-27^{\circ}$ with a step of $0.002^{\circ}$. The structural characteristics of the samples were determined by the Rietveld refinement using the MRIA program (Zlokazov and Chernyshev 1992). Diffraction profiles were modeled by the Voigt function (Toraya 1986) taking into account anisotropic line broadening (Popa 1998).

The X-ray powder diffraction patterns were processed and the crystallite size of the NTD component of the nanocomposite was calculated $(D=0.9 \lambda / \beta \cos \theta$, where $\lambda=1.54051 \AA, 2 \theta \sim 25^{\circ}, \beta$ is the integral peak width, the standard deviation is $5 \%$ ) using the program for the processing of X-ray diffraction patterns of nanosized and

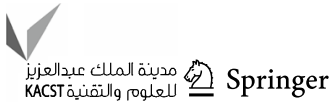


amorphous compounds and calculations of characteristics of the substructure (Kuz'micheva et al. 2016).

IR spectra were recorded on a Bruker EQUINOX 55 Fourier-transform infrared spectrometer with a $2 \mathrm{~cm}^{-1}$ resolution in the $400-4000 \mathrm{~cm}^{-1}$ frequency range.

Scanning electron microscopy (SEM) studies were carried out on a high-resolution JSM 7500F electron microscope using the procedures described by Obolenskaya et al. (2012).

The sorption capacities with reference to nitrogen were measured by the Brunauer-Emmet-Teller (BET) method using the procedures described by Kravchenko et al. (2016).

X-ray photoelectron spectroscopy (XPS) was recorded on a PHOIBOS $150 \mathrm{MCD}$ spectrometer (Al Ka radiation) under vacuum $\left(3 \times 10^{-9}\right.$ Torr $)$ at a pass energy of 30 and $10 \mathrm{eV}$ for panoramic spectrum and separate lines, respectively. The power of the source was $225 \mathrm{~W}$. The step size was $1 \mathrm{eV}$ for panoramic spectrum and $0.1 \mathrm{eV}$ for separate lines. All binding energies were calibrated with contaminant carbon $(\mathrm{C} 1 \mathrm{~s}=284.6 \mathrm{eV})$ as a reference.

Differential scanning calorimetry (DSC). The thermal effects observed under dynamic heating conditions were measured on a Netzsch DSC 204 Phoenix differential scanning calorimeter in a dry gas atmosphere (argon) at a flow rate of $100 \mathrm{~mL} / \mathrm{min}$ in the temperature range of $20-600{ }^{\circ} \mathrm{C}$ at a temperature scan rate of $10{ }^{\circ} \mathrm{C} / \mathrm{min}$ under an inert atmosphere. The weight of powdered samples was $7-10 \mathrm{mg}$. The samples were placed in standard aluminum crucibles with a pierced lid. The results were processed using the Netzsch Proteus software.

Photocatalytic activity (PCA) was studied on the model decomposition reaction of methyl orange (MeO, CAS no. 547-58-0) organic dyes according to (Domoroshchina et al. 2017).

Adsorption properties. Study of the adsorption capacity of the samples was performed according to (Kravchenko et al. 2016) on an aqueous solution with concentration of phosphorus $10 \mathrm{mg} / \mathrm{l}\left(C_{\text {initial }}\right)$ prepared from the standard solutions of $\mathrm{P}(\mathrm{V})$ and $\mathrm{As}(\mathrm{V})$.

\section{Results and discussion}

The crystal structure of zeolite $\mathrm{Y}$ of the composition $M_{x / n}\left(\mathrm{H}_{2} \mathrm{O}\right)_{y}\left[\mathrm{Al}_{x} \mathrm{Si}_{192-x} \mathrm{O}_{384}\right]$, where $x$ is the number of $\mathrm{Al}$ atoms per asymmetric unit and $M$ is the $n$-valent cation (sp. gr. $\mathrm{Fd} \overline{3} \mathrm{~m}, z=1$ ) (Serykh 2014; Kaduk and Faber 1995; Baerlocher et al. 2007; Kubasov 1998; Bushuev 2011; Frising and Leflaive 2008) (Fig. 1), is based on $\mathrm{TO}_{4}$ tetrahedra, where $\mathrm{T}=\mathrm{Si}$ or $\mathrm{Al}(\mathrm{Si} / \mathrm{Al}>1.5)$, which share vertices to form truncated cuboctahedra of 24 tetrahedra (sodalite units) enclosing small cavities ( $\beta$-cages); the volume of the inner cavity is $\sim 0.15 \mathrm{~nm}^{3}$ and the diameter is $0.66 \mathrm{~nm}$ (Kubasov 1998; Bushuev 2011) (Fig. 1b). The cuboctahedra are linked together by hexagonal prisms (Fig. 1b). There are large cavities, or $a$-cavities (supercages), with a volume $\sim 0.81 \mathrm{~nm}^{3}$ and a diameter of $\sim 1.2 \mathrm{~nm}$ between the cuboctahedra and hexagonal prisms (Fig. 1b) (Serykh 2014; Kubasov 1998; Bushuev 2011). In the framework of zeolite $\mathrm{Y}$, the negative charge of the $\mathrm{AlO}_{4}$ tetrahedron is compensated by $\mathrm{Na}^{+}$cations и/или $\mathrm{H}^{+}$which can occupy the zeolite pores together with water molecules.

$X$-ray powder diffraction analysis. Figure 2 presents the $\mathrm{X}$-ray powder diffraction patterns of zeolite $\mathrm{Y}$ and the NTD/Y nanocomposite. A comparison of these diffraction patterns shows that NTD is present in NTD/Y in the nanocrystalline state $(D=5.7(3) \mathrm{nm})$ (sell parameters $a=3.7794 \AA, c=9.5048 \AA$ have been determined by 101,004 and 200 reflections) the characteristic reflections at $2 \theta \sim 25^{\circ}, 2 \theta \sim 38^{\circ}, 2 \theta \sim 48^{\circ}$ belong to anatase (JCPDS No. 46-1238) (Fig. 2b). In addition, there is a significant redistribution of the intensities of some reflections of zeolite (enclosed in ovals) (Fig. 2a, b), which is indicative of changes in the composition of the zeolite $\mathrm{Y}$ component of the nanocomposite compared to that of the initial zeolite.

The crystal structure refinement of zeolite Y [the initial atomic coordinates of the zeolite framework with $\mathrm{Si} /$ $\mathrm{Al}=5.2 \pm 0.5$ and $a=24.49 \AA$ were taken from the
Fig. 1 A network of $\mathrm{TO}_{4}$ tetrahedra $(\mathrm{T}=\mathrm{Si}, \mathrm{Al})$ linked to each other in the structure of zeolite Y (a), the framework structure of zeolite $Y$ composed of sodalite units linked via hexagonal prisms (b) (Baerlocher et al. 2007) a

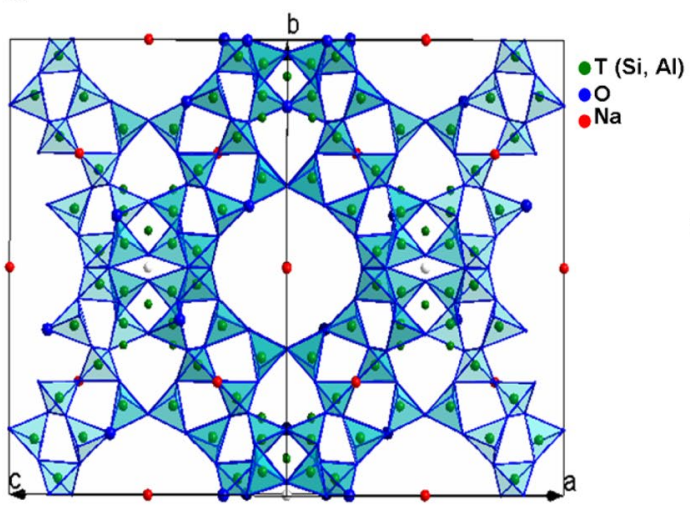

b

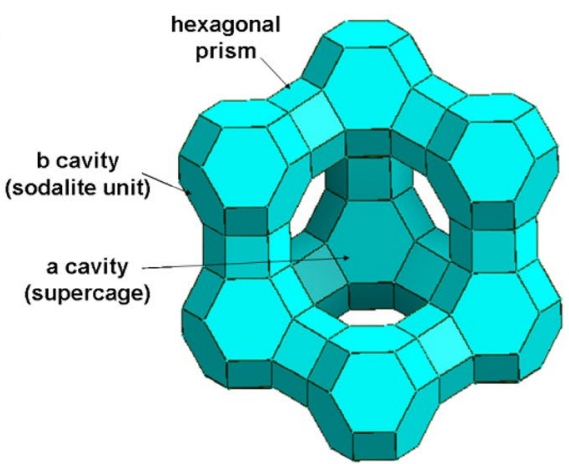




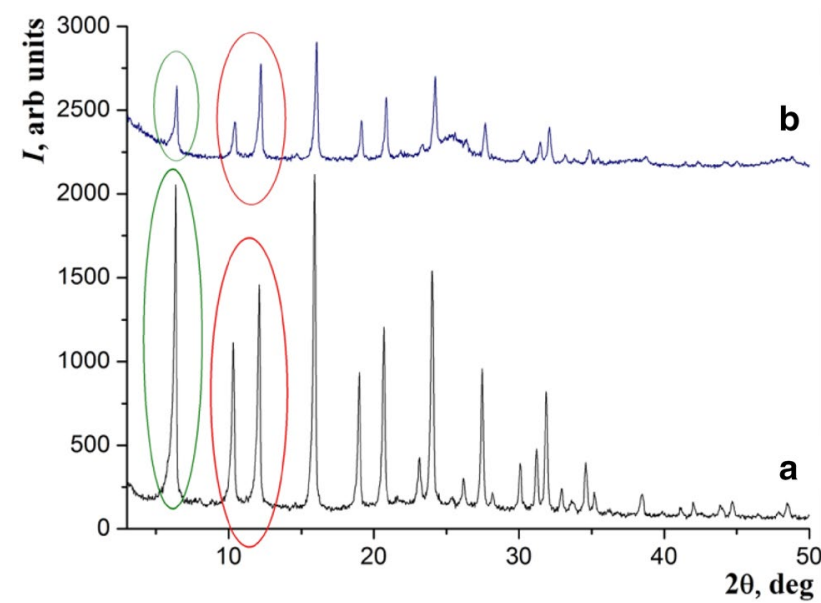

Fig. 2 X-ray powder diffraction patterns: a of the initial zeolite Y; b of the NTD/Y nanocomposite

Table 1 Crystallographic parameters of zeolite $\mathrm{Y}$ and the NTD/Y nanocomposite

\begin{tabular}{lcc}
\hline Characteristics & $\mathrm{Y}$ & $\mathrm{NTD} / \mathrm{Y}$ \\
\hline$A, \AA$ & $24.3530(2)$ & $24.2377(3)$ \\
$B_{\text {iso }}(\mathrm{T}), \AA$ & $1.033(3)$ & $1.665(7)$ \\
$B_{\text {iso }}(\mathrm{O}), \AA$ & $0.515(8)$ \\
$P$ (s.o.f.) $\left(\mathrm{Ow} 1^{\mathrm{a}}\right)$ & $0.394(3)$ & $0.35(2)$ \\
$P$ (s.o.f.) $\left(\mathrm{Ow} 2^{\mathrm{a}}\right)$ & $0.55(1)$ & $0.35(2)$ \\
$P$ (s.o.f.) $\left(\mathrm{Ow} 3^{\mathrm{a}}\right)$ & $0.65(1)$ & $0.12(2)$ \\
$P$ (s.o.f). $\left(\mathrm{Ow} 4^{\mathrm{a}}\right)$ & $0.39(1)$ & $0.25(2)$ \\
$\chi^{2} / R_{\mathrm{wp}} / R_{\exp }$ & $0.78(1)$ & $5.7 / 0.037 / 0.0145$ \\
\hline
\end{tabular}

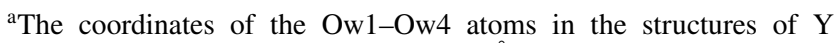
and NTD/Y are equal within $3 \sigma(0.003 \AA)$ and are as follows: Ow1, - 0.8980 .0210 .309 ; Ow2, 0.0420 .0420 .461 ; Ow3, 0.3450 .345 0.448; Ow4, 0.8980 .0210 .309

study (Jeanjean et al. 1989)] (Table 1) was performed by varying, apart from the peak profile parameters and background, the parameter $a$ of the cubic unit cell, the displacement parameter $B_{\text {iso }}$ for the Si atom in the only independent $\mathrm{T}$ position $(\mathrm{T}=\mathrm{Si}, \mathrm{Al})$ with the coordinates - 0.05480 .12610 .0360 , and one overall parameter $B_{\text {iso }}$ for four independent oxygen atoms $(\mathrm{O} 1,-0.10770 .0000$ $0.1077 ; \mathrm{O} 2,-0.0009-0.00090 .1391 ; \mathrm{O} 3,-0.0345$ 0.0749 0.0749; O4, 0.06870 .06870 .3264 ).

In the course of the refinement, hard constraints were imposed on the interatomic $\mathrm{T}-\mathrm{O}$ and $\mathrm{O}-\mathrm{O}$ distances $(<2.7 \AA)$, and therefore, the atomic coordinates of the zeolite framework changed only slightly.

In the first step of the refinement, it was assumed that no small molecules are present in the pores of zeolite $\mathrm{Y}$ (i.e., anhydrous zeolite). However, the value $\chi^{2}=91$ (quality of the refinement) shows that this assumption is not true.
For the second step of the refinement, we used a model, which assumed the presence of water molecules in the zeolite pores. The positions of water oxygen atoms (Ow1-Ow4) were determined by simulated annealing (Zhukov et al. 2001). The atoms were successively added to the model if they did not deviate from the initial positions by more than $0.5 \AA$, in the course of the refinement and this led to a decrease in the $\chi^{2}$ value. This allowed us to determine the positions of four oxygen atoms (Ow1-Ow4) in the zeolite pores, to which the fixed $B_{\text {iso }}$ value was assigned. For these atoms, both the coordinates and the site occupancy factors ( $p$, s.o.f) were refined, which resulted in a significant reduction in $\chi^{2}$ (to 8.8). Table 1 gives the selected structural parameters for this refinement model. The quality of the fit for zeolite $\mathrm{Y}$ is presented in Fig. 3.

The increase in $B_{\text {iso }}(\mathrm{T})$ indicates a decrease in the total occupation of this position, which is due to a decrease in the $\mathrm{Si} / \mathrm{Al}$ modulus, which is indeed smaller $(\mathrm{Si} / \mathrm{Al}=2.3)$ than in the initial structure $(\mathrm{Si} / \mathrm{Al}=5)$ (Jeanjean et al. 1989). The refinement of the mixed occupation of Si/Al turned out to be uninformative due to the proximity of atomic numbers, and as a consequence, the atomic scattering curves. $\mathrm{R}$ factors were practically unchanged in the process of various models refinement.

The X-ray powder diffraction pattern of the NTD/Y nanocomposite (Fig. 4) clearly shows broadened peaks in positions corresponding to the anatase structure (JCPDS No. 46-1238). Therefore, we used a two-phase model for the Rietveld refinement. The main phase was described by a model of zeolite $\mathrm{Y}$ with the pores occupied by water molecules and with the same refined parameters (Table 1). The second phase was described using a standard anatase model,

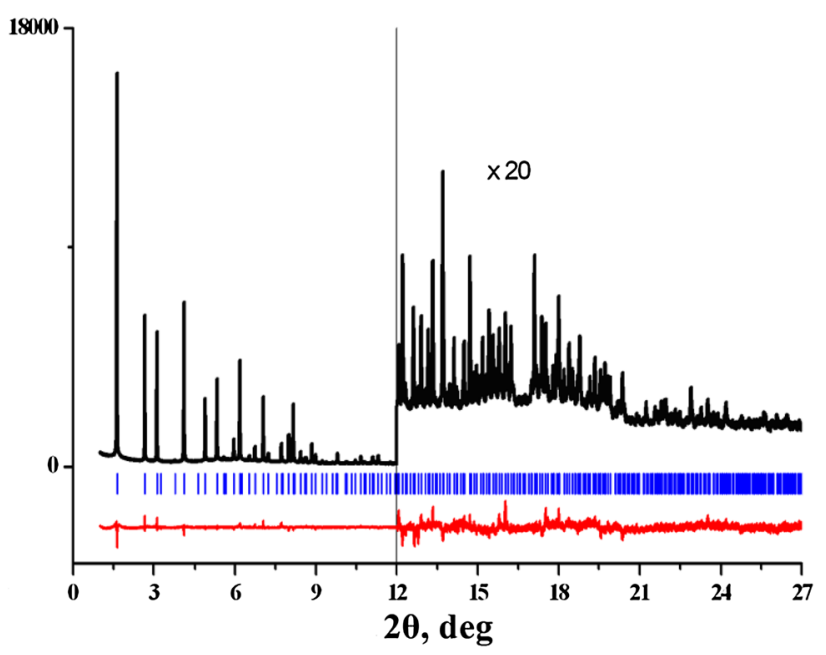

Fig. 3 Rietveld refinement of the synchrotron X-ray powder diffraction pattern of $\mathrm{Y}$ zeolite (red line-background level; blue line-Y zeolite theoretical diffraction pattern; black line- $-\mathrm{Y}$ zeolite diffraction pattern)

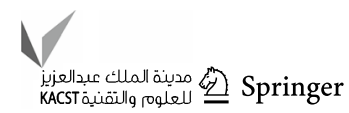




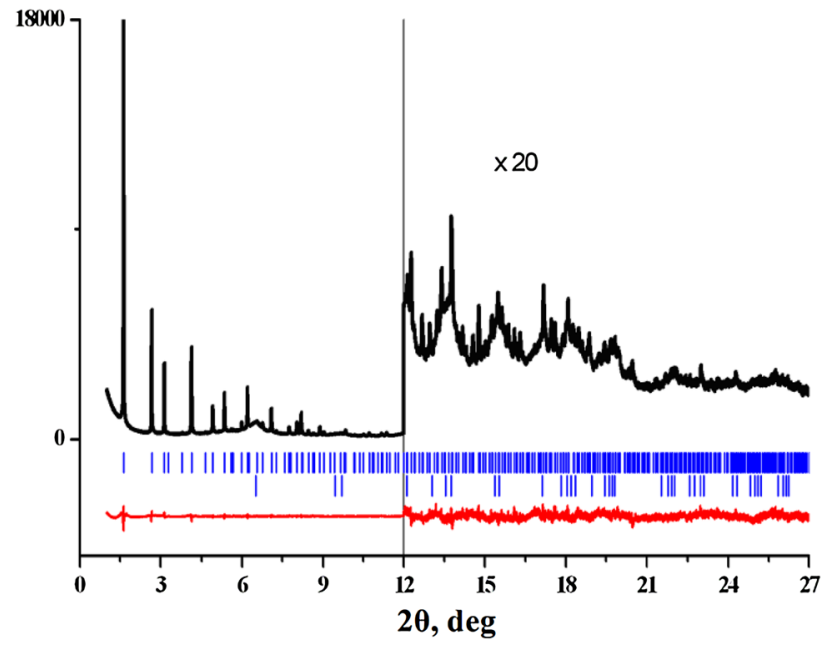

Fig. 4 Two-phase Rietveld refinement of the synchrotron X-ray powder diffraction pattern of the NTD/Y nanocomposite (red line-background level; blue line-NTD/Y nanocomposite theoretical diffraction pattern; black line-NTD/Y nanocomposite diffraction pattern)

in which only the tetragonal unit cell parameters $a$ and $c$ of anatase along with the parameters of the peak profile function were refined. The quality of the fit of the two-phase model is presented in Fig. 4.

As can be seen from the comparison of the unit cell parameters of zeolite $\mathrm{Y}$ and the NTD/Y nanocomposite (Table 1), the unit cell parameter for the nanocomposite is substantially smaller than that for zeolite $\mathrm{Y}$, which can be attributed only to a decrease in the amount of water (the diameter of the water molecule is $\sim 0.3 \mathrm{~nm}$ ) in the zeolite pores with diameter $0.74 \mathrm{~nm}$ (Fig. 1). The synthesis of the nanocomposite under the above-mentioned conditions is not accompanied by the replacement of $\mathrm{Al}$ ions $\left(r_{\mathrm{Al}}^{\mathrm{IV}}=0.39 \AA\right)$ with $\mathrm{Ti}$ ions $\left(r_{\mathrm{Ti}}^{\mathrm{IV}}=0.42 \AA\right)$ in the $\mathrm{T}$ position $(\mathrm{T}=\mathrm{Si}$ or $\mathrm{Al})$. If this would be the case, this would lead to a substantial decrease in the displacement parameter $B_{\text {iso }}(\mathrm{T})$ and an increase in the unit cell parameter, which was not observed after the structure refinement (Table 1). Thus, there are water molecules in the pores of the initial zeolite $\mathrm{Y}$ (it is possible that a certain amount remains in the zeolite $\mathrm{Y}$ in the nanocomposite NTD/Y).

IR spectroscopy. The IR spectrum (Fig. 5, Table 2) of NTD/Y shows a band at $960 \mathrm{~cm}^{-1}$, which is absent in the IR spectrum of zeolite Y.

In some studies (Zhang et al. 1995; Zhao et al. 2009; Smirnov and Van de Graaf 1996), this band was assigned to Ti-O-Si symmetric stretching vibrations assuming the replacement of Si atoms with $\mathrm{Ti}$ (Zhang et al. 1995); alternatively (Chong et al. 2015), this fact was attributed to the location of NTD on the surface of zeolite without its inclusion in the framework. The X-ray powder diffraction data combined with the IR spectroscopic data suggest that the

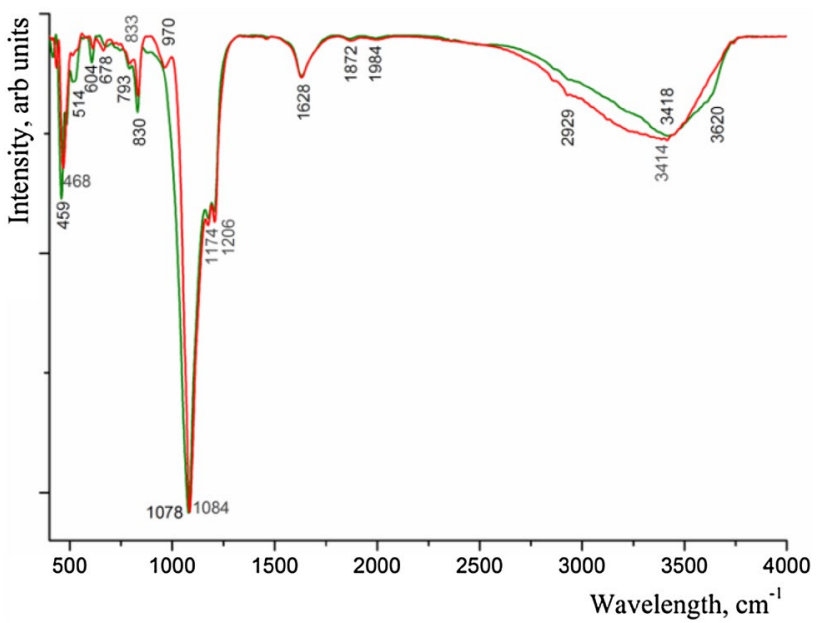

Fig. 5 IR spectra of zeolite Y (green) and the NTD/Y nanocomposite (red)

band at $960 \mathrm{~cm}^{-1}$ in the spectrum of NTD/Y can be assigned to NTD particles on the zeolite surface (group I).

The intensity redistribution for the bands in the region of $400-800 \mathrm{~cm}^{-1}$ for NTD/Y is due to the overlapping of Ti-O stretching bands and vibrational bands of $\mathrm{SiO}_{4}$ and $\mathrm{AlO}_{4}$ tetrahedra (Alwash et al. 2013; Ba-Abbad et al. 2012). The observed shift of the bands in this region may be due to intermolecular interactions (Fedorova et al. 2015). The bands at $\sim 460$ and $\sim 480 \mathrm{~cm}^{-1}$ correspond to bending vibrations of the six-membered rings (hexagonal prisms) of zeolite Y. A decrease in the intensity of the band at $\sim 460 \mathrm{~cm}^{-1}$ and the disappearance of the band at $484 \mathrm{~cm}^{-1}$ in the IR spectrum of NTD/Y are apparently attributed to a change in the Si/Al ratio (Knops-Gerrits et al. 1997). This experimental fact does not contradict the results of a full-profile analysis of the initial zeolite $\mathrm{Y}$ and zeolite $\mathrm{Y}$ in the composition of the nanocomposite NTD/Y (Table 1).

The band at $1628 \mathrm{~cm}^{-1}$ responsible for $\mathrm{H}-\mathrm{O}-\mathrm{H}$ bending vibrations of zeolite water molecules (Kostrikin 2015; Saikia and Parthasarathy 2010) is identical in the spectra of both $\mathrm{Y}$ and NTD/Y. The bands at $3150-3630 \mathrm{~cm}^{-1}$ are also associated with zeolite water and correspond to antisymmetric and symmetric stretching vibrations of isolated $\mathrm{OH}$ groups (Kostrikin 2015). The intensity of the band at $~ 3400 \mathrm{~cm}^{-1}$ in the spectrum of $\mathrm{Y}$ is equal to that for NTD/Y, but this band in the spectrum of NTD/Y is shifted to lower frequencies accompanied by a slight broadening. The shift of the maxima of $(\mathrm{OH})$ stretching vibrations to lower frequencies in the spectrum of NTD/Y attests to the involvement of $\mathrm{OH}$ groups in the formation of hydrogen bonds of different strength (Kostrikin 2015). The band at $3620-3630 \mathrm{~cm}^{-1}$ is assigned to $\mathrm{O}-\mathrm{H}$ vibrations of zeolite water located in the cavities of the framework (Kostrikin 2015). The absence of this band in the spectrum of NTD/Y is in good agreement with the 
Table 2 Assignment of the bands in the IR spectra of the initial zeolite $\mathrm{Y}$ and the NTD/Y nanocomposite (Alwash et al. 2013; Mamedova 2016; Ba-Abbad et al. 2012; Fedorova et al. 2015; Knops-Gerrits et al. 1997; Kostrikin 2015; Saikia and Parthasarathy 2010; Shishelova et al. 2010; Dikii et al. 2009)

\begin{tabular}{|c|c|c|}
\hline Assignment & $\mathrm{Y}$ & NTD/Y \\
\hline$\delta(\mathrm{O}-\mathrm{Si}-\mathrm{O})+\delta(\mathrm{O}-\mathrm{Al}-\mathrm{O})$ & 422 & 436 \\
\hline$\delta\left(\mathrm{TO}_{4}\right)(\mathrm{T}=\mathrm{Si}, \mathrm{Al}), \nu(\mathrm{TiO})$ & $\begin{array}{l}459 \\
484\end{array}$ & 468 \\
\hline$\delta(\mathrm{T}-\mathrm{O}-\mathrm{Si})$ & 514 & $514 s h$ \\
\hline$\nu_{\mathrm{s}}(\mathrm{SiOSi})+\nu_{\mathrm{s}}(\mathrm{SiOAl}), \nu(\mathrm{TiO})$ & $\begin{array}{l}604, \\
678, \\
744 s h\end{array}$ & $614,667,718 s h$ \\
\hline$\nu_{\mathrm{s}}(\mathrm{SiOSi})$ & $\begin{array}{l}793 \\
830\end{array}$ & $\begin{array}{l}795 \\
833\end{array}$ \\
\hline$\nu_{\mathrm{as}}\left(\mathrm{SO}_{4}\right), \nu_{\mathrm{as}}\left(\mathrm{TiO}_{6}\right)$ & & 960 \\
\hline$\nu_{\text {as }}\left(\mathrm{TO}_{4}\right)$ & $\begin{array}{l}1080 \\
1175 \\
1203\end{array}$ & $1084,1174,1206$ \\
\hline Presence of residual structure-forming organic additive $\left[\delta\left(\mathrm{CH}_{2}\right)\right]$ & $1458 w$ & $1458 w$ \\
\hline$\delta\left(\mathrm{H}_{2} \mathrm{O}\right) \mathrm{H}-\mathrm{O}-\mathrm{H}$ bending vibrations of zeolite water molecules & 1628 & 1628 \\
\hline Presence of residual structure-forming organic additive $[\nu(\mathrm{CO})]$ & $\begin{array}{l}1868 w \\
1983 w\end{array}$ & $\begin{array}{l}1872 w \\
1984 w\end{array}$ \\
\hline $\mathrm{H}-\mathrm{O}-\mathrm{H}$ bending vibrations & $2944 w$ & $2939 w$ \\
\hline $\begin{array}{l}\nu(\mathrm{OH}) \\
\mathrm{O}-\mathrm{H} \text { vibrations of zeolite water }\end{array}$ & $\begin{array}{l}3418 b r \\
3620 s h\end{array}$ & $3414 b r$ \\
\hline
\end{tabular}

$b r$ broad, $w$ weak, sh shoulder results of the Rietveld refinement of the crystal structure (Table 1): a decrease in the amount of water in the pores of the zeolite Y component of the NTD/Y nanocomposite.

X-ray photoelectron spectroscopy (XPS). According to the XPS data the local Ti2p spectrum of NTD (Fig. 6a) synthesized in a similar method for comparison (Kuz' micheva et al. 2010), contains components $\sim 462.7$ and $\sim 457.1 \mathrm{eV}$ responsible for $\mathrm{Ti} 2 \mathrm{p} 3_{/ 2}$ of $\mathrm{Ti}^{4+}$ and $\mathrm{Ti} 2 \mathrm{p}_{1 / 2}$ of $\mathrm{Ti}^{4+}$, respectively (Wagner et al. 2003). On the NTD/Y Ti2p spectrum (Fig. 6a) these components are slightly shifted ( 462.1 and $\sim 457.9 \mathrm{eV}$ ), which are probably due to the sample charging under X-ray radiation. Moreover, the intensity ratio of these components is different-the intensity of $\mathrm{Ti} 2 \mathrm{p}_{3 / 2}$ of $\mathrm{Ti}^{4+}$ component became greater compared to $\mathrm{Ti} 2 \mathrm{p}_{1 / 2}$ of $\mathrm{Ti}^{4+}$. Additionally, the component $\sim 453.7 \mathrm{eV}$ responsible for $\mathrm{Ti}^{4+}$ ions connected with $\mathrm{OH}$ groups or water has appeared on NTD/Y spectrum (Fig. 6a) (Wagner et al. 2003).

The local O1s spectrum of pure NTD (Fig. 6b) contains a wide asymmetric band formed by the imposition of two bands: $\sim 530.1$ and $\sim 532.5 \mathrm{eV}$ corresponding to Ti-O bonds (Wagner et al. 2003) and $\mathrm{OH}$ groups (Kuz'micheva et al. 2010), respectively. a

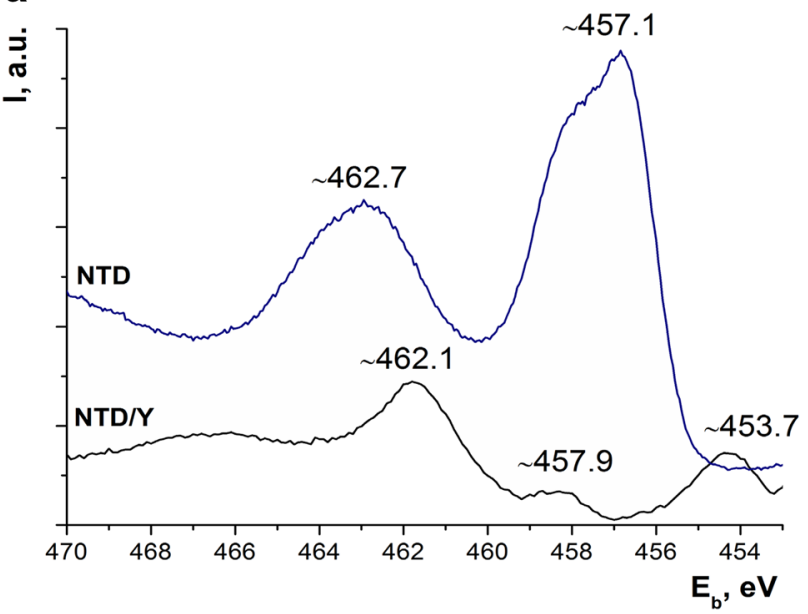

b

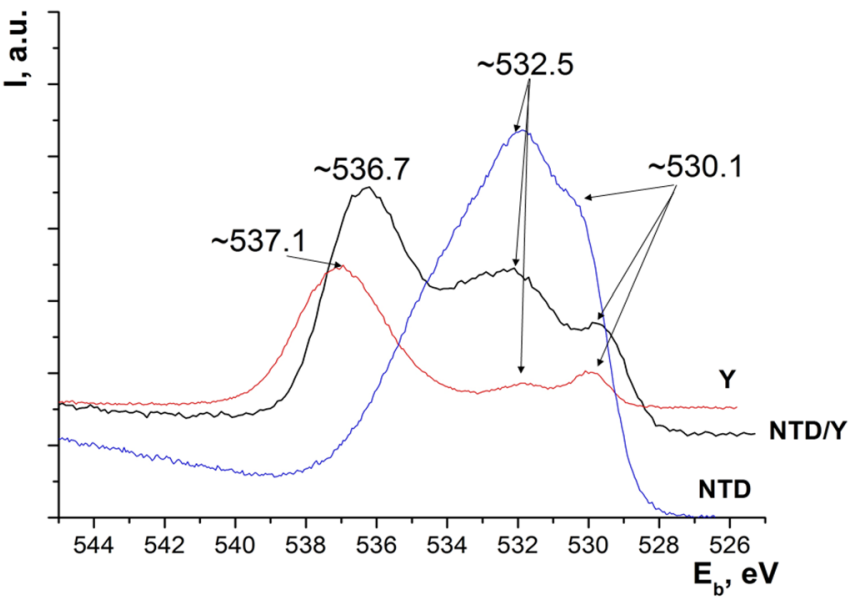

Fig. 6 X-ray photoelectron spectrum Ti2p of NTD and NTD/Y (a); X-ray photoelectron spectra O1s of NTD, zeolite Y and NTD/Y (b) 
The local spectra of the initial Y and NTD/Y (Fig. 6b) contain components $\sim 530.1 \mathrm{eV}$ (T-O or/and Ti-O bands) and $\sim 532.5 \mathrm{eV}$ (less conspicuous for $\mathrm{Y}$ ), which indicates a larger number of $\mathrm{OH}$ groups on NTD/Y surface compared to the initial Y. The additional components $\sim 537.1 \mathrm{eV}$ on $\mathrm{Y}$ spectrum and $\sim 536.7 \mathrm{eV}$ on NTD/Y one (the shift is due to the sample charging) are responsible for surface-adsorbed water molecules (Wagner et al. 2003; Sanjines et al. 1994) and characterize the chemical interaction between the initial zeolite and NTD in the formation of NTD/Y (Zhang et al. 2013).

Differential scanning calorimetry (DSC). The thermal effects observed in the DSC thermograms of zeolite $\mathrm{Y}$ and the NTD/Y nanocomposite (Fig. 7) are characterized by different maximum temperatures: two endothermic effects at $t_{1}=68.4{ }^{\circ} \mathrm{C}, t_{2}=520{ }^{\circ} \mathrm{C}$ for $\mathrm{Y}$ (Fig. 7a); two endothermic effects at $t_{1}=70.3{ }^{\circ} \mathrm{C}, t_{2}=490{ }^{\circ} \mathrm{C}$ for NTD/Y (Fig. 7a).

The endothermic effects in the temperature ranges of 20-200 and 490-600 ${ }^{\circ} \mathrm{C}$ are associated with desorption of water molecules. The asymmetry of the first endothermic peak for the starting zeolite Y (Fig. 7a) is attributed to the overlapping of two endothermic effects: a decrease in the amount of physically adsorbed surface water $\left(68.4{ }^{\circ} \mathrm{C}\right)$, which is easily removed upon heating, and water of crystallization (in the case under consideration, zeolite water), which is released at temperatures below $300^{\circ}$ (Shishelova et al. 2010) (the peak at $180{ }^{\circ} \mathrm{C}$ ) (Fig. 7b).

In the DSC thermogram of the NTD/Y nanocomposite, the first endothermic peak corresponds to desorption of physically adsorbed surface water (the peak at $70.3{ }^{\circ} \mathrm{C}$ ) (Fig. 7a). The area under the first endothermic peak of zeolite $\mathrm{Y}$ is larger than the area under the corresponding peak of NTD/Y; the thermal effect is 184.7 and $157 \mathrm{~J} / \mathrm{g}$ for $\mathrm{Y}$ and NTD/Y, respectively. This is evidence that the amount of water (both surface water and crystallization or zeolite water) in zeolite $\mathrm{Y}$ is larger compared to the NTD/Y nanocomposite. These results are in agreement with the data of IR spectroscopy.

The weak endothermic effects at $490{ }^{\circ} \mathrm{C}$ for NTD/Y and at $520{ }^{\circ} \mathrm{C}$ for $\mathrm{Y}$ are apparently attributed to elimination of constitutional water, which is present in the crystal structure in the form of $\mathrm{OH}^{1-}$ ions and which is liberated in the temperature range from 300 to $1000{ }^{\circ} \mathrm{C}$.

At temperatures above $500{ }^{\circ} \mathrm{C}$, the band at $\sim 1600 \mathrm{~cm}^{-1}$ disappears in the IR spectra and the band at $3620-3630 \mathrm{~cm}^{-1}$, which corresponds to $\mathrm{O}-\mathrm{H}$ stretching vibrations of zeolite water located in the cavities of zeolite, has a lower intensity (Dikii et al. 2009; Evdokimova and Lankin 2015).

The in situ synthesis of NTD/Y nanocomposites was performed at $95( \pm 2){ }^{\circ} \mathrm{C}$, at which the crystallization (zeolite) water is not released from zeolite, but physically absorbed surface water can be eliminated. A decrease in the water content in NTD/Y compared to Y (Table 1) can be attributed to the synthesis conditions (heating to $t=93( \pm 2){ }^{\circ} \mathrm{C}$ ).

Scanning electron microscopy (SEM). In the zeolite Y (more precisely, HNaY) under consideration, the size of the supercages is $0.74 \mathrm{~nm}$ and the total pore volume $V_{\Sigma}=0.371 \mathrm{~cm}^{3} / \mathrm{g}$ with the BET specific surface area $S_{\mathrm{BET}}=490.6 \mathrm{~m}^{2} / \mathrm{g}$. The morphology of zeolite Y observed by SEM is represented by hexagons and individual faceted elongated octahedra $\left(N_{\text {SEM }} \leq 750 \mathrm{~nm}\right)$ (Fig. 8a), while on the SEM microphotographs of NDT/Y spherical particles with size $\left(N_{\mathrm{SEM}} \sim 10-55 \mathrm{~nm}\right)$ forming associates $\left(N_{\mathrm{SEM}}\right.$ $\leq 300 \mathrm{~nm}$ ) on the surface of faceted shapes are observed (Fig. 8b).

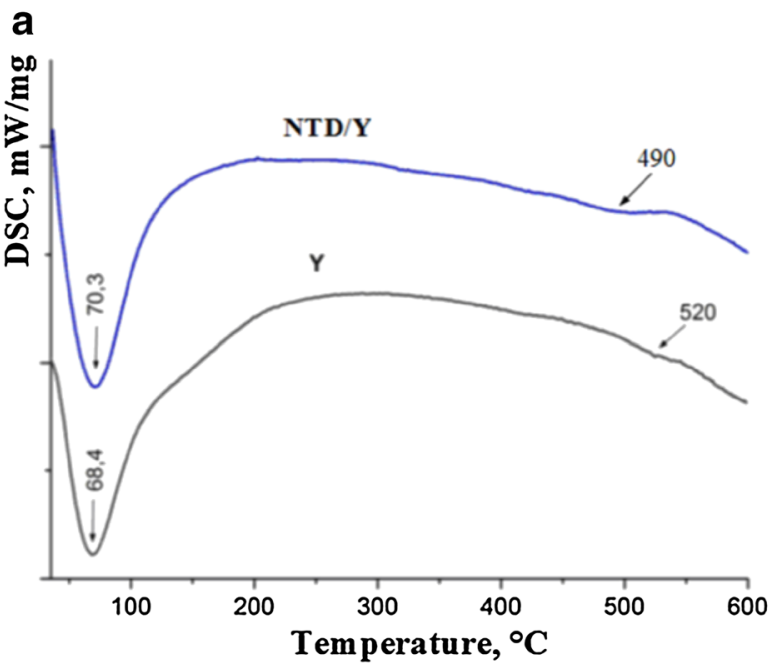

b

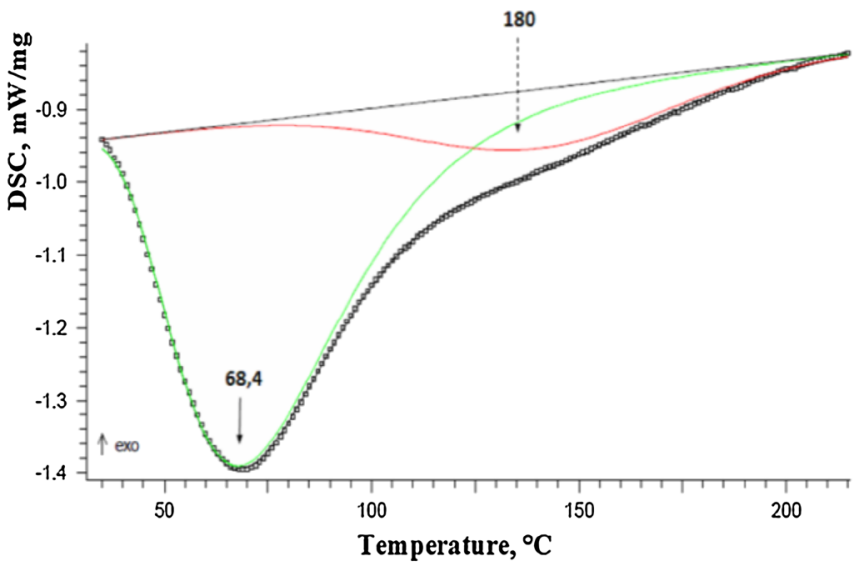

Fig. 7 DSC thermograms: a of zeolite $\mathrm{Y}$ and the NTD/Y nanocomposite; $\mathbf{b}$ with the separation of the first asymmetric peak into two peaks for zeolite $\mathrm{Y}$ 

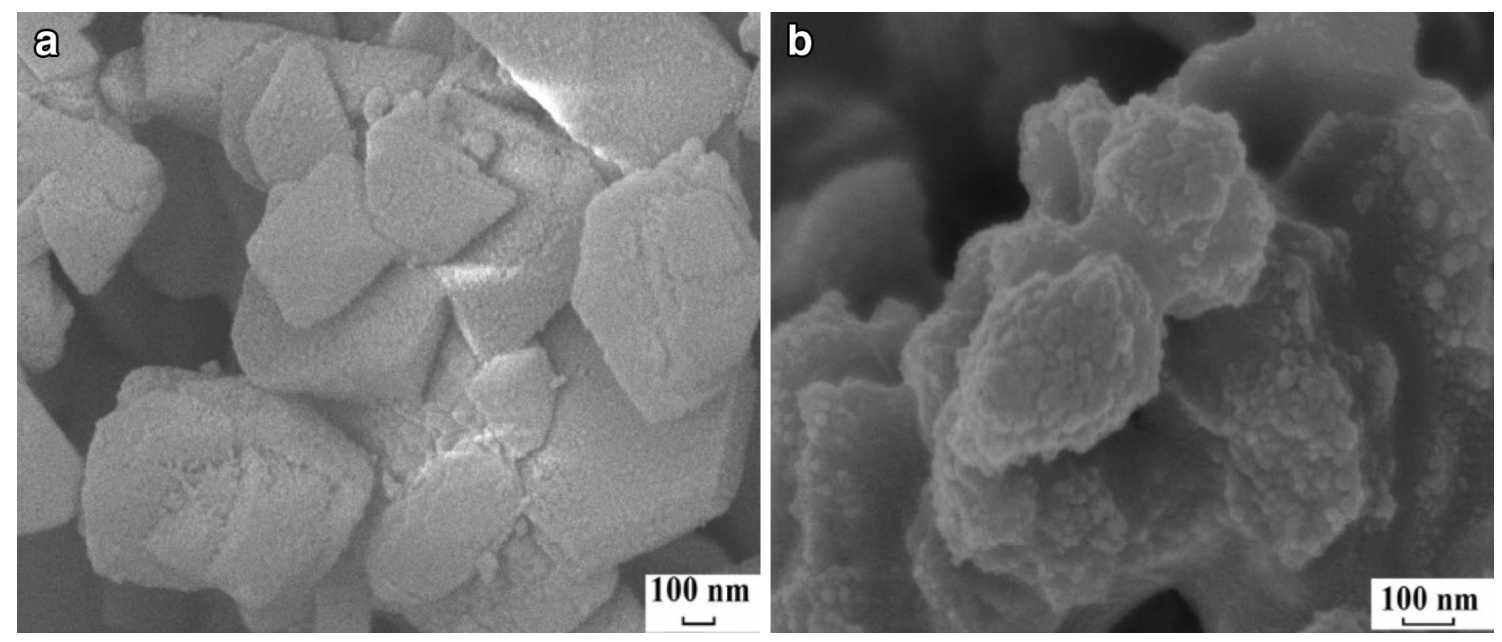

Fig. 8 Microphotographs: $\mathbf{a}$ of the initial zeolite $\mathrm{Y}$; $\mathbf{b}$ of the NTD/Y nanocomposite

The sorption capacities. The specific surface area of the $\mathrm{NTD} / \mathrm{Y}$ nanocomposite $\left(S_{\mathrm{BET}}=552.8 \mathrm{~m}^{2} / \mathrm{g}\right)$ was found to be larger than that of the initial zeolite $\mathrm{Y}\left(490.6 \mathrm{~m}^{2} / \mathrm{g}\right)$. The factors responsible for changes in the specific surface area of the NTD/Y nanocomposite were considered (Wang et al. 2008, 2015; Maraschi et al. 2014). The specific surface area of the "amorphous NTD/Y" nanocomposite prepared by the sol-gel method is smaller than that of the initial zeolite Y. In the study (Wang et al. 2015), a decrease in the specific surface area of the nanocomposite was attributed to small sizes of amorphous NTD particles, which penetrate into the zeolite framework. With an increase in the NTD loading, the pores are filled with NTD particles (the size of the particles deposited on the surface of the zeolite estimated by SEM is 20-100 nm), and then the deposition of amorphous NTD occurs on the surface of zeolite, which is accompanied by an increase in the specific surface area of NTD/Y (Wang et al. 2015).

The $S_{\mathrm{BET}}$ value and the pore volume of the "nanoanatase/Y" nanocomposite (prepared by means of the wet impregnation method) were found to decrease with an increase in the $\mathrm{TiO}_{2}$ loading (Wang et al. 2008). This is attributed to dispersion of NTD on the surface of zeolite and the fact that the zeolite pores are partially blocked by NTD particles, the size of which increases with an increase in the $\mathrm{TiO}_{2}$ loading due to their aggregation.

A change in the specific surface area of NTD/Y compared to the initial Y $\left(S_{\mathrm{BET}}=175 \mathrm{~m}^{2} / \mathrm{g}\right)$ was observed for nanocomposites synthesized by the mechanical mixing with annealing and in the absence of annealing using different types of NTD (Maraschi et al. 2014):

- Decrease in the specific surface area of sample 1 $\left(S_{\mathrm{BET}}=135 \mathrm{~m}^{2} / \mathrm{g}\right)$ with the initial Degussa P25 (anatase + rutile);
- Increase in the specific surface area of sample 2 $\left(S_{\mathrm{BET}}=228 \mathrm{~m}^{2} / \mathrm{g}\right.$ ) with the initial amorphous $\mathrm{TiO}_{2}$ and nano-anatase in NTD/Y upon annealing of the nanocomposite at $350{ }^{\circ} \mathrm{C}$;

- Increase in the specific surface area of sample 3 $\left(S_{\mathrm{BET}}=215 \mathrm{~m}^{2} / \mathrm{g}\right)$ with the initial nano-anatase and nano-anatase in NTD/Y.

For the in situ synthesized NTD/Y nanocomposite under consideration, a decrease in the amount of water molecules in the pores of NTD/Y is one of the factors responsible for an increase in its specific surface area compared to the initial zeolite Y. The total surface of all particles in the nanocomposite is also increased taking into account their surface roughness $\left[172.6 \mathrm{~m}^{2} / \mathrm{g}\right.$ for NTD/Y and $30-50 \mathrm{~m}^{2} / \mathrm{g}$ for the initial zeolite $\mathrm{Y}$ (Kravchenko et al. 2016)]. Besides, it cannot be ruled out that nanocrystalline NTD with the anatase structure in the NTD/Y nanocomposite contributes to an increase in the specific surface area, as it was observed for sample 3 (Maraschi et al. 2014) considered above.

Thereby, the NTD/Y nanocomposite differs from the initial $\mathrm{Y}$ zeolite with smaller particle sizes, a large number of active $\mathrm{OH}$ groups and lower water content on the surface, a smaller content of water molecules in the pores of the zeolite and a larger specific surface area. NTD/Y differs from NTD with a smaller particle size, larger specific surface area and a large number of active $\mathrm{OH}$ groups and water content on the nanocomposite surface.

Adsorption properties. The adsorption properties of NTD are due to the surface hydroxyl groups with a high reactivity, which are formed at crystallite sizes (coherent scattering regions) below $10 \mathrm{~nm}$ at their amount close to 100\% (Dadachov 2006).

The adsorption capacity of zeolites is affected by its modulus ( $\mathrm{Si} / \mathrm{Al})$ : with a decrease in the modulus, the hydrophilic 
properties of the zeolite are enhanced (Alwash et al. 2013) and the total concentration of the Bronsted acid centers increases due to the formation of protons for the conservation of the system electroneutrality witch most likely determines the adsorption properties of zeolite $\mathrm{Y}$ and NTD/Y under investigation.

Zeolite $\mathrm{Y}$ exhibits a greater adsorption capacity for the extraction $\mathrm{P}(\mathrm{V})$ ions $\left(R_{\mathrm{P}(\mathrm{V})}=96.56 \%\right)$ from the aqueous medium (Domoroshchina et al. 2017; Kravchenko et al. 2016) compared to $\mathrm{As}(\mathrm{V})$ ions $\left(R_{\mathrm{As}(\mathrm{V})}=68.80 \%\right)($ Fig. $9 \mathrm{a})$, that is probably due to the size factor: $\mathrm{As}(\mathrm{V})$ radius $(0.33 \AA)$ is greater than $\mathrm{P}(\mathrm{V})$ one $(0.17 \AA)$.

The adsorption capacity of NTD/Y nanocomposite increases compared to the initial zeolite $\mathrm{Y}: R_{\mathrm{P}(\mathrm{V})}=98.07 \%$ and $R_{\mathrm{As}(\mathrm{V})}=99.56 \%$ (Fig. 9a), moreover, the degree of these ions extraction by pure $\mathrm{TiO}_{2}(D=5.3(3) \mathrm{nm}$; $S_{\mathrm{BET}}=39.7 \mathrm{~m}^{2} / \mathrm{g}$ ) is smaller compared to NTD $/ \mathrm{Y}$ : $R_{\mathrm{P}(\mathrm{V})}=94.62 \%, R_{\mathrm{As}(\mathrm{V})}=96.34 \%$.

Photocatalytic properties. The photocatalytic activity (PCA) of NTD/Y in the model degradation reaction of Methyl Orange under UV light is higher compared to initial Y and pure NDT (Fig. 9b).

The photocatalytic activity of NTD under UV depends on the content of surface hydroxyl groups responsible for the adsorption of the dye on the surface and considered the main active species involved in the dye degradation process (Alwash et al. 2013; Grätzel 2003).

The role of zeolite in increasing PCA of nanocomposites with NTD is to delocalize the excited electrons of titanium dioxide, which allows minimizing the rate of electron-hole pairs' recombination (Lazau et al. 2011).

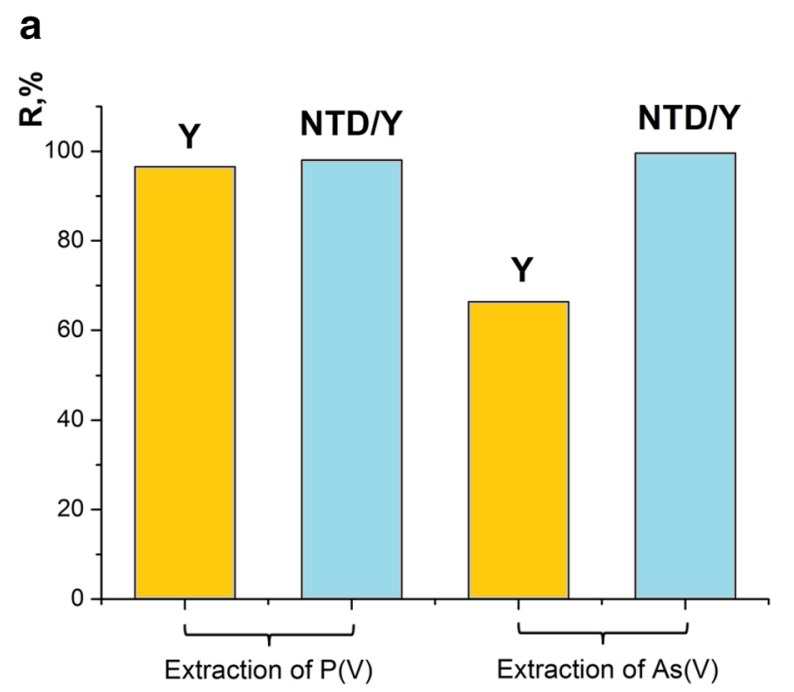

Fig. 9 The degree of $\mathrm{P}(\mathrm{V})$ and $\mathrm{As}(\mathrm{V})$ ions extraction from the aqueous medium by the initial Y and NTD/Y (a). Dependence of the interpolated values of the negative natural logarithm of the relative
The chemical composition of zeolites can be described in general form as $M_{j / n}\left[\left(\mathrm{AlO}_{2}\right)_{j}\left(\mathrm{SiO}_{2}\right)_{y}\left(\mathrm{H}_{2} \mathrm{O}\right)_{z}\right]$, where $\mathrm{M}^{\mathrm{n}+}$ or $\mathrm{H}^{+}$cations compensate for system electroneutrality with decreasing zeolite acidity (decrease in $\mathrm{Si} / \mathrm{Al}$ modulus). The composition of the zeolite $\mathrm{Y}$ surface in the $\mathrm{H}^{+}$form $\left(\mathrm{Na}(\mathrm{H})_{58}\left[\mathrm{Al}_{58} \mathrm{Si}_{134} \mathrm{O}_{384}\right]\left(\mathrm{H}_{2} \mathrm{O}\right)_{240}\right)$ with the Bronsted acid centers can be represented as follows:<smiles>C[Al](C)(C)O[Si](C)(C)O[Si](C)(C)O[Si](C)(C)C</smiles>

It is not excluded that Lewis acid centers are formed in the nanocomposite NTD/Y with a decrease in the amount of water on its surface:<smiles>C[Al](C)O[Al](C)(C)O[Si](C)(C)O[Al](C)(C)O[In](C)O</smiles>

According to (Salama et al. 2007), the PCA of nanocomposites increases compared to NTD and zeolites with increasing Lewis acidity centers, as has been revealed for NTD/MOR composites. By adjusting the Si/Al ratio, the nature of the $\mathrm{M}$ cations, the degree of substitution of $\mathrm{M}^{\mathrm{n}+}$ by $\mathrm{H}^{+}$and the depth of removal of the hydration water, it is

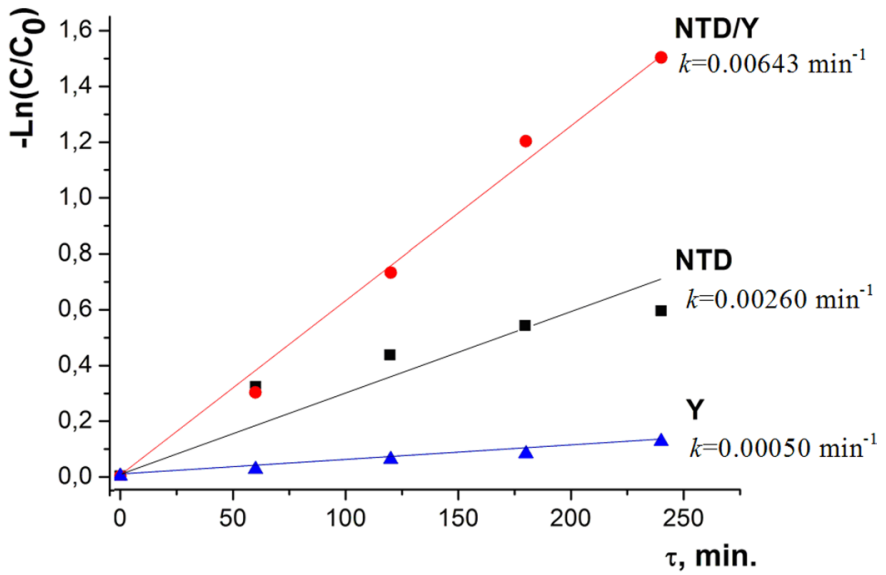

change in $\mathrm{MeO}$ concentration $\left(-\ln \left(\mathrm{c} / \mathrm{c}_{0}\right)\right)$ on the duration $(\tau)$ of $\mathrm{UV}$ irradiation $(26 \mathrm{~W})$ of the photoreaction mixture in the presence of the initial Y, pure NTD and NTD/Y (b) 
possible to vary the acidity of the zeolites within a very wide range, and hence to control their photocatalytic activity.

The high activity of the NTD/Y photocatalyst compared to the initial components (zeolite $\mathrm{Y}$ and NTD) is due to the high specific surface area of the nanocomposite and the high dispersity of the nano-anatase on its surface (Fig. 9b). This conclusion is consistent with the literature data (Liu et al. 1992; Zhang et al. 2013; Guesh et al. 2016).

It should be noted that incorporation of NTD particles into the zeolite pores during the synthesis of NDT/Y nanocomposite increases the photocatalytic activity to a greater extent than the presence of NTD on the zeolite surface in nanocomposite (Easwaramoorthi and Natarajan 2009). The synthesis of nanocomposite by the ion exchange method, and in some cases, high-temperature annealing contributes to the presence of NTD particles in the pores of zeolite, which has not been envisaged in this work.

\section{Conclusion}

Study by X-ray diffraction and IR spectroscopy demonstrated that in the in situ synthesized nanocomposite based on zeolite Y, nanocrystalline anatase is present on the surface of the zeolite and is not incorporated into the framework (X-ray powder diffraction, SEM).

A smaller amount of water (X-ray powder diffraction, IR spectroscopy, DSC) in the pores of the zeolite Y component of nano-anatase/Y compared to the initial $\mathrm{Y}$ was found. This process leads to an increase in the specific surface area. The size of the faceted particles of zeolite Y $\left(N_{\mathrm{SEM}} \leq 750 \mathrm{~nm}\right)$ exceeds the size of the spherical nanocomposite particles forming associates $\left(N_{\mathrm{SEM}} \leq 300 \mathrm{~nm}\right)$ on the surface of faceted shapes.

The presence of anatase nanoparticles with crystallite size $D=5.7(3) \mathrm{nm}$ on the surface of zeolite particles, the increase in $\mathrm{OH}$ groups content and the decrease in the water content on NTD/Y surface compared to Y (XPS) and the decrease in the water content in NTD/Y pores compared to $\mathrm{Y}$ (X-ray powder diffraction, IR spectroscopy, DSC) were established.

The increase in photocatalytic activity in the model degradation reaction of $\mathrm{MeO}$ under $\mathrm{UV}$ light is due to a higher specific surface area and a smaller particle size in NTD/Y compared to $\mathrm{Y}$ and NTD, a larger content of hydroxyl groups and a smaller water content on NTD/Y surface compared to $\mathrm{Y}$ and a larger content of hydroxyl groups and a larger water content on NTD/Y surface compared to NTD.

The increase in adsorption capacity of nanocomposite nano-anatase/Y for the extraction of $\mathrm{P}(\mathrm{V})$ and $\mathrm{As}(\mathrm{V})$ ions from aqueous media compared to the initial $\mathrm{Y}$ and pure NTD is caused by a higher specific surface area of NTD/Y and a large content of hydroxyl groups on NTD/Y surface compared to pure NTD and Y.

All these facts indicate the predominant role of the specific surface area and the content of active groups on NTD/Y surface in the realization of photocatalytic activity in the decomposition reaction of $\mathrm{MeO}$ under $\mathrm{UV}$ and adsorption activity of nanocomposite.

Acknowledgements This study was financially supported by RFBR (research project No. 15-03-01289). The X-ray diffraction part of this research was supported by the Ministry of Education and Science of the Russian Federation (Grant no. RFMEFI61616X0069). We also thank the ESRF for access to the beamline ID22 (experiment MA-3313).

\section{References}

Alwash AH, Abdullah AZ, Ismail N (2013) $\mathrm{TiO}_{2}$-zeolite Y catalyst prepared using impregnation and ion-exchange method for sonocatalytic degradation of Amaranth dye in aqueous solution. J Chem Mol Nucl Mater Metall Eng 7:375-383

Ba-Abbad MM, Kadhum AA, Mohamad AB, Takriff MS, Sopian K (2012) Synthesis and catalytic activity of $\mathrm{TiO}_{2}$ nanoparticles for photochemical oxidation of concentrated chlorophenols under direct solar radiation. Int J Electrochem Sci 6:4871-4888

Baerlocher C, McCusker LB, Olson DH (2007) Atlas of zeolite framework types. Elsevier Inc., New York

Breck D (1974) Zeolite molecular sieves-structure, chemistry and use. Wiley-lnterscience, New York

Bushuev YG (2011) Zeolites. Computer modeling of zeolite materials. Ivanovo State University of Chemistry and Technology, Ivanovo

Chong MN, Tneu ZY, Poh PE, Jin B, Aryal R (2015) Synthesis, characterization and application of $\mathrm{TiO}_{2}$-zeolite nanocomposites for the advanced treatment of industrial dye wastewater. J Taiwan Inst Chem Eng 50:288-296

Dadachov M (2006) Novel adsorbents and process of making and using same. US Pat. 0144793

Demina PA, Kuz'michev AA, Tsybinsky AM, Obolenskaya LN, Kuz'micheva GM, Domoroshchina EN, Savinkina EV (2014) Synthesis, characterization and adsorption behavior of Mo(VI) and $\mathrm{W}(\mathrm{VI})$ ions on titanium dioxide nanoparticles containing anatase modification. Appl Nanosc 4:979-987. https://doi. org/10.1007/s13204-013-0279-9

Dikii NP, Medvedova EP, Fedorets ID, Khlapova NP, Lutsai NS, Lyashko YV, Medvedev DV, Gavrik AP (2009) Thermomodification of nanopowder of natural clinoptilolite. J V.N. Karazin Kharkiv Natl Univ Ser Biol Pharm 880:84-90

Domoroshchina E, Kravchenko G, Kuz'micheva G (2017) Nanocomposites of zeolite-titanium(IV) oxides: preparation, characterization, adsorption, photocatalytic and bactericidal properties. J Cryst Growth 468:199-203. https://doi.org/10.1016/j.jcrys gro.2017.02.001

Easwaramoorthi S, Natarajan P (2009) Characterisation and spectral properties of surface adsorbed phenosafranine dye in zeolite-Y and ZSM-5: photosensitisation of embedded nanoparticles of titanium dioxide. Microporous Mesoporous Mater 117:541-550. https://doi.org/10.1016/j.micromeso.2008.07.042

Evdokimova VA, Lankin SV (2015) Structural changes of clinoptylolite in the process of dehydration. Sci Tech Volga Reg Bull Pharm (Russian journal) 2:19-24. https://elibrary.ru/item.asp?id=23696 025

Fedorova OA, Kulakova II, Sotnikova YA, Zhilenko MP, Krutyakov YA, Olenin AY, Rakhmanov EV, Safronov AV, Khoroshutin AV

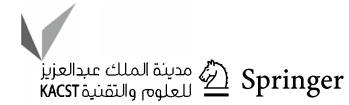


(2015) Methods of optical spectroscopy. Moscow State University, Moscow

Fitch AN (2004) The high resolution powder diffraction beam line at ESRF. J Res Natl Inst Stand Technol 109:133-142. https://doi. org $/ 10.6028 /$ jres. 010

Frising T, Leflaive P (2008) Extraframework cation distributions in X and Y faujasite zeolites: a review. Microporous Mesoporous Mater 114:27-63. https://doi.org/10.1016/j.micromeso.2007.12.024

Galhotra P, Navea J, Larsen S, Grassian V (2009) Carbon dioxide $\left(\mathrm{C}^{16} \mathrm{O}_{2}\right.$ and $\left.\mathrm{C}^{18} \mathrm{O}_{2}\right)$ adsorption in zeolite $\mathrm{Y}$ materials: effect of cation, adsorbed water and particle size. Energy Environ Sci 2:401-409. https://doi.org/10.1039/b814908a

Ginter DM, Bell AT, Radke SJ (1992) Synthesis of microporous materials. Symp Synth Microporous Mater, Van Nostrand, New York

Grätzel M (2003) Dye-sensitized solar cells. J Photochem Photobiol C 4:145-153. https://doi.org/10.1016/S1389-5567(03)00026-1

Guesh K, Mayoral A, Márquez-Álvarez C, Chebude Y, Díaz I (2016) Enhanced photocatalytic activity of $\mathrm{TiO}_{2}$ supported on zeolites tested in real wastewaters from the textile industry of Ethiopia. Microporous Mesoporous Mater 225:88-97. https://doi. org/10.1016/j.micromeso.2015.12.001

Ismagilov ZR, Tsikoza LT, Shikina LV, Zarytova VF, Zinoviev VV, Zagrebelnyi SN (2009) Synthesis and stabilization of nanosized titanium dioxide. Russ Chem Rev 78:873-885. https://doi. org/10.1070/RC2009v078n09ABEH004082

Ito M, Fukahori Sh, Fujiwara T (2014) Adsorptive removal and photocatalytic decomposition of sulfamethazine in secondary effluent using TiO2-zeolite composites. Environ Sci Pollut Res 21:834 842. https://doi.org/10.1007/s11356-013-1707-9

Jansson I, Suárez S, Garcia-Garcia EF, Sánchez B (2015) Zeolite-TiO 2 hybrid composites for pollutant degradation in gas phase. Appl Catal B Environ 178:100-107. https://doi.org/10.1016/j.apcat b.2014.10.022

Jeanjean J, Aouali L, Delafosse D, Dereigne A (1989) Crystal structure of different dealuminated Y-type zeolites determination of framework vacancies and non-framework species. J Chem SOC Furaday Trans I 85:2771-2783. https://doi.org/10.1039/f19898502771

Kaduk JA, Faber J (1995) Crystal Structure of zeolite Y as a function of ion exchange. Rigaku J 12:14-34

Kamegawa T, Kido R, Yamahana D, Yamashita H (2013) Design of $\mathrm{TiO}_{2}$-zeolite composites with enhanced photocatalytic performances under irradiation of UV and visible light. Microporous Mesoporous Mater 165:142-147. https://doi.org/10.1016/j.micro meso.2012.08.013

Klein H, Kirschhock C, Fuess H (1994) Adsorption and diffusion of aromatic hydrocarbons in zeolite $\mathrm{Y}$ by molecular mechanics calculation and X-ray powder diffraction. J Phys Chem 98:1234512360. https://doi.org/10.1021/j100098a033

Knops-Gerrits PP, De Vos DE, Feijen EJ, Jacobs PA (1997) Raman spectroscopy on zeolites. Microporous Mater 8:3-17. https://doi. org/10.1016/S0927-6513(96)00088-0

Kostrikin AV (2015) Hydroxo and hydroxooxo compounds of the elements of germanium and titanium subgroups: synthesis, structure and properties. Dissertation, RUDN University, Moscow

Kravchenko GV, Domoroshchina EN, Kuz'micheva GM, Gaynanova AA, Amarantov SV, Pirutko LV, Tsybinsky AM, Sadovskaya NV, Kopylova EV (2016) Zeolite-titanium dioxide nanocomposites: preparation, characterization, and adsorption properties. Nanotechnol Russ 11:579-592. https://doi.org/10.1134/s199507801 6050098

Kubasov AA (1998) Zeolites-boiling stones. Soros Educ J 7:70-76 (Russian journal)

Kubota M, Nakabayashi T, Matsumoto Y, Shiomi T, Yamada Y, Ino K, Yamanokuchi H, Matsui M, Tsunoda T, Mizukami F, Sakaguchi K (2008) Selective adsorption of bacterial cells onto zeolites.
Colloids Surf B Biointerfaces 64:88-97. https://doi.org/10.1016/j. colsurfb.2008.01.012

Kuwahara Y, Aoyama J, Miyakubo K, Eguchi T, Kamegawa T, Mori K, Yamashita $\mathrm{H}$ (2012) $\mathrm{TiO}_{2}$ photocatalyst for degradation of organic compounds in water and air supported on highly hydrophobic FAU zeolite: structural, sorptive, and photocatalytic studies. J Catal 285:223-234. https://doi.org/10.1016/j.jcat.2011.09.031

Kuz'micheva GM, Savinkina EV, Obolenskaya LN, Belogorokhova LI, Mavrin BN, Chernobrovkin MG, Belogorokhov AI (2010) Synthesis, characterization, and properties of nanoscale titanium dioxide modifications with anatase and $\eta-\mathrm{TiO}_{2}$ structures. Crystallogr Rep 55:866-871. https://doi.org/10.1134/S1063774510050287

Kuz'micheva GM, Podbelsky VV, Stepanov AN, Gaynanova AA (2016) Program for the processing of diffraction patterns of nanoscale and amorphous substances and calculation of the substructure characteristics. Rus. Pat. 2017610699

Lazau C, Ratiu C, Orha C, Pode R, Manea F (2011) Photocatalytic activity of undoped and $\mathrm{Ag}$-doped $\mathrm{TiO}_{2}$-supported zeolite for humic acid degradation and mineralization. Mater Res Bull 46:1916-1921. https://doi.org/10.1016/j.materresbull.2011.07.026

Liu X, Iu K, Thomas J (1992) Encapsulation of $\mathrm{TiO}_{2}$ in zeolite Y. Chem Phys Lett 195:163-168. https://doi.org/10.1016/00092614(92)86129-6

Mamedova GA (2016) Chemical modification of the natural mineralmordenite. Proceedings of Voronezh State University. Series: Chemistry. Biology. Pharmacy (Russian journal) 1:16-20

Maraschi F, Sturini M, Speltini A, Pretali L, Profumo A, Pastorello A, Kumar V, Ferretti M, Caratto V (2014) $\mathrm{TiO}_{2}$-modified zeolites for fluoroquinolones removal from wastewaters and reuse after solar light regeneration. J Environ Chem Eng 2:2070-2076. https://doi. org/10.1016/j.jece.2014.08.009

Obolenskaya LN, Kuz'micheva GM, Savinkina EV, Sadovskaya NV, Zhilkina AV, Prokudina NA, Chernyshev VV (2012) Influence of the conditions of the sulfate method on the characteristics of nanosized anatase-type samples. Russ Chem Bull 61:2032-2039. https://doi.org/10.1007/s11172-012-0286-0

Park H, Hwang J, Chang J, Kim J, Kim D (2003) Titania photocatalyst and its preparing method. US Pat., 6566300

Popa NC (1998) The (hkl) dependence of diffraction-line broadening caused by strain and size for all laue groups in Rietveld refinement. J Appl Cryst 31:176-180. https://doi.org/10.1107/s0021 889897009795

Saikia BJ, Parthasarathy G (2010) Fourier Transform infrared spectroscopic characterization of Kaolinite from Assam and Meghalaya, Northeastern India. J Mod Phys 1:206-210. https://doi. org/10.4236/jmp.2010.14031

Salama TM, Ali IO, Mohamed MM (2007) Synthesis and characterization of mordenites encapsulated titania nanoparticles: photocatalytic degradation of meta-chlorophenol. J Mol Catal A Chem 273:198-210. https://doi.org/10.1016/j.molcata.2007.03.071

Sanjines R, Tang H, Berger H, Gozzo F, Margaritondo G, Levy F (1994) Electronic structure of anatase $\mathrm{TiO}_{2}$ oxide. J Appl Phys 76:2945-2951. https://doi.org/10.1063/1.356190

Serykh AI (2014) Formation, nature and physico-chemical properties of cationic centers in catalytic systems based on high-silica zeolites. Dissertation. Zelinsky Institute of Organic Chemistry

Shishelova TI, Sozinova TV, Konovalova AN (2010) Workshop on spectroscopy. Water in minerals. Textbook, Russian Academy of Natural History, Moscow

Smirnov KS, Van de Graaf B (1996) On the origin of the band at $960 \mathrm{~cm}^{-1}$ in the vibrational spectra of Ti-substituted zeolites. Microporous Mesoporous Mater 7:133-138. https://doi. org/10.1016/0927-6513(96)00023-5

Toraya H (1986) Whole-powder-pattern fitting without reference to a structural model: application to X-ray powder diffraction data. 
J Appl Cryst 19:440-447. https://doi.org/10.1107/s002188988 6088982

Treacy M, Higgins J (2007) International Zeolite Association. Structure Commission., collection of simulated XRD powder patterns for zeolites. Elsevier, Amsterdam

Wagner CD, Naumkin AV, Vass AK, Allison JW, Powell CJ, Rumble JR (2003) NIST XPS database. Version 3.4

Wang CC, Lee CK, Lyu MD, Juang LC (2008) Photocatalytic degradation of C.I. basic violet 10 using $\mathrm{TiO}_{2}$ catalysts supported by $Y$ zeolite: an investigation of the effects of operational parameters. Dye Pigment 76:817-824. https://doi.org/10.1016/j.dyepi g.2007.02.004

Wang JJ, Jing YH, Ouyang T, Chang CT (2015) Preparation of 13X from Waste Quartz and Photocatalytic Reaction of Methyl Orange on $\mathrm{TiO}_{2} / \mathrm{ZSM}-5,13 \mathrm{X}$ and Y-Zeolite. J Nanosci Nanotechnol 15:6141-6149 https://www.ncbi.nlm.nih.gov/pubmed/26369215

Xu Y, Langford C (1997) Photoactivity of titanium dioxide supported on MCM41, zeolite X, and zeolite Y. J Phys Chem B 101:3115-3121

Zendehdel M, Kalateh Z, Mortezaii Z (2014) Photocatalytic activity of the nano-sized $\mathrm{TiO}_{2} / \mathrm{NaY}$ zeolite for removal of methylene blue. $\mathrm{J}$ Nov Appl Sci 3:135-141

Zhang S, Kobayashi T, Nosaka Y, Fujii N (1995) Characterization of titanium oxide encapsulated zeolites and its photocatalytic application for NO decomposition (E). Denki Kagaku oyobi Kogyo Butsuri Kagaku 63:927-931

Zhang W, Bi F, Yu Y, He H (2013) Phosphoric acid treating of ZSM-5 zeolite for the enhanced photocatalytic activity of TiO2/HZSM-5. J Mol Catal A Chem 372:6-12. https://doi.org/10.1016/j.molca ta.2013.02.002

Zhao D, Wang J, Zhao X, Zhang J (2009) $\mathrm{TiO}_{2} / \mathrm{NaY}$ composite as photocatalyst for degradation of omethoate. Chem Res Chin Univ 25:543-549

Zhukov SG, Chernyshev VV, Babaev EV, Sonneveld EJ, Schenk H (2001) Application of simulated annealing approach for structure solution of molecular crystals from X-ray laboratory powder data. Z Kristallogr 216:5-9. https://doi.org/10.1524/zkri.216.1.5.18998

Zlokazov VB, Chernyshev VV (1992) MRIA-a program for a full profile analysis of powder multiphase neutron-diffraction timeof-flight (direct and Fourier) spectra. J Appl Cryst 25:447-451. https://doi.org/10.1107/s0021889891013122

Publisher's Note Springer Nature remains neutral with regard to jurisdictional claims in published maps and institutional affiliations. 